\title{
Study on the Temporal and Spatial Pattern of Achnatherum splendens Community in Hulun Lake Area
}

\author{
Jianhua Mao \\ College of Geography and Environment Science, Northwest Normal University, Lanzhou 730070, \\ China \\ mjhgis@163.com
}

\section{Keywords: A. splendens community; Landsat; Spatio-temporal changes and pattern; Hulun Lake}

\begin{abstract}
Achnatherum splendens community is one of the typically non-zonal vegetation occurred in arid and semi-arid regions. It plays important roles in maintaining species diversity and promoting regional livestock production. In this paper, methods of decision tree classification and change detection were adopted to identify the Achnatherum Splendens community from Landsat remote sensing data with two periods: 1985 and 2015, and its spatio-temporal changes and pattern were investigated. The results show that: (1) the distribution of Achnatherum Splendens community around the Hulun Lake area increased significantly over the past 30 years with area increasing by 148.39 ha, where the patches of area $<0.5$ hectares increased fastest; (2) the NDVI and RVI value of Achnatherum Splendens community are clearly higher than that of typical steppes, suggesting it could produce more biomass compared others; and (3) the distribution of Achnatherum Splendens community mainly occurred in area of slope $<5^{\circ}$ and adret, where generally hold more soil moisture, salinity and nutrient elements such as N,P and K.
\end{abstract}

\section{Introduction}

Meadow steppe is one of the important components of the grassland ecosystem at semi-arid areas, generally located at the transition zone between semi-humid and semi-arid areas and between open forest steppe and dry steppe[1]. Its growth is highly related to the surface soil moisture and annual average temperature[2,3] and is also affected by some terrain factors, among which the altitude affects most, followed by the grade and the exposure affects the smallest[4]. Meadow steppe enjoying good soil texture, rich vegetation types and flourishing growth is an important natural grassland and pasture[5], which has strong ecological service function and resistance to animal husbandry in all types of grasslands[6]. But with the global climate changes, meadow steppe is also inevitably affected[7]. In the present study of meadow grassland, the impact of climate change on the meadow steppe could be divided into two aspects: positive and negative[8-10]. The climate warming enhances the moisture cycling, warm and moisture air mass going deeper into inland which brings more precipitation for arid and semi-arid areas and is conducive to promoting the vegetation growth in grasslands[11]. At the same time, due to the rising average surface temperature and increasing evaporation, giving the surface evaporation is much larger than precipitation, the soil water content of grassland is seriously reduced and the soil salinity-alkalinity has increased, which caused the changes of regional species composition marked by the growth frustration of wet vegetation in the meadow steppe and the significant growth of salt and drought tolerant vegetation[12].

Hulun Lake is located in northeast China. Recent study shows that in recent decades, its water level has decreased and its area has shrank significantly. The increase in regional evapotranspiration and the reduction of precipitation in the whole drainage basin caused by the climate warming are the main reasons for the decline of water level in Hulun Lake[13-15]. As the important confluence area of water resources in the region, the change of hydrology and water quality in Hulun Lake will affect the composition and distribution of vegetation in this area. Studies have shown that grassland degradation in this area is serious, the proportion of fine pasture is decreased, the proportion of weeds is increased, the biodiversity of wetland is reduced and the ecological service values as well 
as the ecosystem security are greatly challenged[16-18]. Achnatherum splendens is a vegetation species widely distributed in this region, the constructive species of salt meadow and is usually distributed in the lightly salinized hidden habitat. It is an important species of grassland biodiversity and an important constituent species of grassland biodiversity[19]. Its appearance or disappearance can be used as the indicators of changes in climate, hydrology and other natural elements. Therefore, under the background of regional warming, this paper intends to use remote sensing technology to monitor the spatiotemporal dynamics of Achnatherum splendens community in Hulun Lake area to scientifically understand the impact of climate change on regional ecosystems.

\section{Research Area and Data}

Overview of the Study Area. The study area $\left(117^{\circ} 00^{\prime} 10^{\prime \prime} \mathrm{E}-117^{\circ} 41^{\prime} 40^{\prime \prime} \mathrm{E}\right.$, $48^{\circ} 30^{\prime} 40^{\prime \prime} \mathrm{N}-49^{\circ} 20^{\prime} 40^{\prime \prime} \mathrm{N}$ ) is located in the northeast of Inner Mongolia Autonomous Region, west to Great Khingan, at the border of China, Russia and Mongolia, covering Manchuria City, the New Barker Left Banner and the New Barr Tiger Right Banner. Its annual average temperature is -5 $2{ }^{\circ} \mathrm{C}$ and the average annual rainfall is $240.8 \mathrm{~mm}$, concentrated in the summer of July to September. The average annual evaporation is $1500 \mathrm{~mm}$ and it is the temperate arid and semi-arid climate. Its terrain was bowl-shaped, declining from west to east and reaching the lowest in the Hulun Lake at 405 meters. Then it gradually rises along the east and reaches the highest at the mountain forest region at 1583 meters, north of the New Barker Left Banner and south of the Great Khingan. The soil type is mainly chernozem or castanozem. The main lakes in the region are Hulun Lake and Buir Lake (China-Mongolia boundary lakes), mainly supplied by rivers of Kelulun River, Wuer River, Hailar River and the Xinkai River. Under the influence of climate and terrain conditions, the main vegetation types in the study area are grassland, woodland and wetland. Among them, the grassland is largest and its dominant species are Stipa baicalensis Roshev, Filifolium sibiricum, Leymus chinensis, etc. While the Achnatherum splendens as a non-zonal grassland community is widely distributed in the region (Fig. 1).

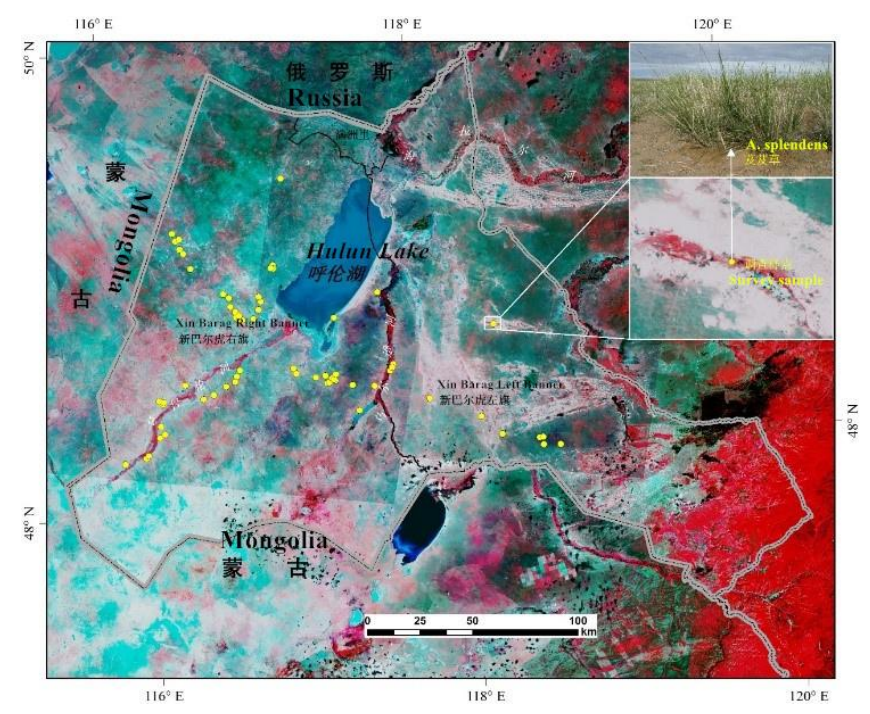

Figure 1. Study Area and Samples of Splendens Field Survey

Data Collection. The remote sensing data for Achnatherum splendens community is mainly extracted through the US land satellites Landsat/TM5 and Landsat 8/OLI, from US Geological Survey (http://glovis.usgs.gov/). Landsat/TM5 was launched in 1984 and stopped working in 2011 due to the aging of its amplifier. The scanning width was $185 \mathrm{~km}$ and the revisit interval was 16 days, with a total of 7 bands and the resolution of 30m. LANDSAT 8 OLI was launched in 2013 and is the subsequent satellite of Landsat Satellite series, maintaining similar band and resolution. Due to the wide coverage of the study area as well as the long revisit interval, it is difficult to collect data covering the entire study area in a single growing season. Therefore, this paper chooses the growth 
date of vegetation from July to August before and after two years of 1985 and 2015 and collects the data of a total of 14 scenes.

The 30-meter DEM elevation data, terrain data selected matched with remote sensing data, mainly from ASTER sensor of Terra, NASA's new generation of ground observation satellite, is available at NASA's website.(http://gDEM.ersdac.jspacesystems.or.jp/ ).

Data authentication of remote sensing accuracy for Achnatherum splendens community is mainly based on the field investigation in Hulun Lake area in July 2015 duringAchnatherum splendens which hand-held GPS machines and digital cameras were used. From the southeast to the northwest, a total of 225 samples were collected, of which 69 were Achnatherum splendens samples ( Fig. 1).

\section{Research Methods}

Classification System. The Hulun Lake area is located in the transition zone between the Mongolian Plateau and the Great Khingan, whose terrain is high on two sides and low in the middle. It is the typical area of temperate steppe and temperate meadow steppe. The constitution of vegetation community is relatively simple, which is mainly the warm-season and drought-enduring vegetation. The types of terrain include grassland, wetland, woodland and water. The main vegetation types and geographical distribution are shown in Table 1.

Table 1 The main vegetation types and geographic distribution in Hulun Lake area

\begin{tabular}{|c|c|c|}
\hline Types & Main composition & Distribution \\
\hline meadow steppe & Achnatherum splendens & $\begin{array}{l}\text { Mainly distributed around the low-lying } \\
\text { watershed }\end{array}$ \\
\hline Typical steppe & $\begin{array}{l}\text { Stipa krylovii, Stipa baicalensis, } \\
\text { Filifolium sibiricum }\end{array}$ & $\begin{array}{l}\text { The vegetation widely distributed in } \\
\text { research area. }\end{array}$ \\
\hline $\begin{array}{l}\text { Wetland } \\
\text { vegetation }\end{array}$ & $\begin{array}{l}\text { Phragmites, Aneurolepididum } \\
\text { chinens }\end{array}$ & $\begin{array}{l}\text { Distributed along the banks of rivers and } \\
\text { lakes. }\end{array}$ \\
\hline Water & Lakes, rivers, swamp & $\begin{array}{l}\text { Mainly Hulun Lake, Buir Lake, Kerulen } \\
\text { River, Wuerxun River, Xinkai River, etc. }\end{array}$ \\
\hline Woodland & $\begin{array}{l}\text { Larix gmelinii, Pinus sylvestris, } \\
\text { White Birch, ASPEN, } \\
\text { Mongolian oak }\end{array}$ & $\begin{array}{l}\text { Mainly distributed in the southern part of } \\
\text { northern part of the Xin Barag Left } \\
\text { Banner and northern part of Great } \\
\text { Khingan. }\end{array}$ \\
\hline
\end{tabular}

The Selection of Classification Index and the Construction of Decision Tree. In determining the application of classification index used, the Normalized Difference Water Index NDWI; Normalized Difference Vegetation Index NDVI and the Ratio Vegetation Index RVI were selected.

The NDWI index (Eq.1) is generally used to extract water information from images which works well but less effective when extracting from water with more architectural in the background. Hulun Lake area has rivers, lakes and many other waters with vegetation as the background. Therefore, the NDWI water index was selected to extract water information.

$$
\text { NDWI }=\frac{P_{\text {Gren }}-P_{N I R}}{P_{\text {Gean }}+P_{\text {NR }}}
$$

The NDVI index (Eq.2) and the RVI (Eq.3) are all vegetation indexes and their respective characteristics can be used to extract different vegetation types. Positive NDVI indicates the cover of vegetation and larger the value, wider the coverage. NDVI is less sensitive to high vegetation area and has enhanced effect on low vegetation coverage area, which could be used to explain the Achnatherum splendens of low coverage and the typical steppe vegetation. The accuracy of RVI index is related to the coverage of vegetation. When the vegetation coverage is high, RVI is very sensitive to vegetation. When the vegetation coverage is less than $50 \%$, the sensitivity is 
significantly lower. It is used to distinguish wetland vegetation, forest land with high coverage from the steppe vegetation with low vegetation coverage.

$$
\begin{array}{r}
\text { NDVI }=\frac{P_{\mathrm{NIR}}-P_{\text {Rad }}}{P_{\mathrm{NIR}}+P_{\text {Rgd }}} \\
\text { RVI }=\frac{P_{\mathrm{NIR}}}{P_{\text {Red }}}
\end{array}
$$

In the formula, $\rho_{\mathrm{NIR}}$ refers to the reflectance of NIR band; $\rho_{\mathrm{Red}}$ refers to the reflectance of red band; $P_{\text {Green }}$ refers to the reflectance of green band.

This paper mainly selects the decision tree classification method for the extraction of the main vegetation types in the study area[20]. Because of the easy extraction of water and non-water, the NDWI water index is used. The species of high vegetation coverage in the study area is wetland vegetation and woodland. Since the steppe is of low coverage, RVI could be used to distinguish steppe and non-steppe due to its high sensitivity to high coverage vegetation. And the average RVI values of forest land and wetland are higher in summer flourishing period which is not easy to be classified. Therefore, the DEM elevation parameters were introduced. In the study area, forest land lies in the southeastern corner of New Barag Left Banner, belonging to the northern part of Great Khingan forest, a relatively high altitude area in the whole research area. The wetland vegetation is mainly distributed around several rivers and sporadic small lakes around the Hulun Lake, all in the valley or depression area of low elevation, so the DEM parameters are used to classify the woodland and wetland vegetation. The NDVI index has enhanced effect for vegetation of low courage, which is used to distinguish between typical steppe and Achnatherum splendens community. The classification decision tree of main vegetation in the whole Hulun Lake area is shown in Fig. 2.

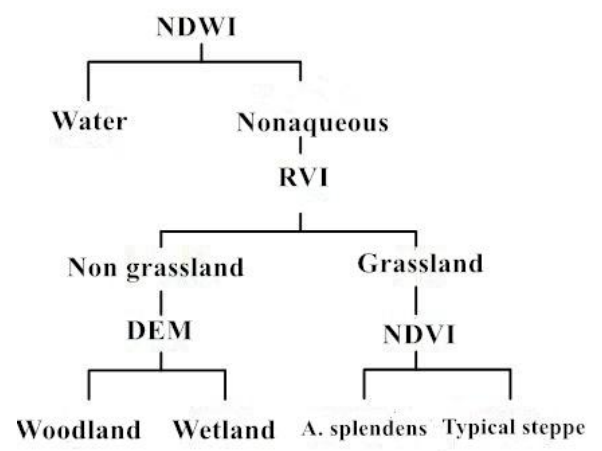

Figure 2. Decision tree for classifying land cover

Change Detection. In this study, the two sets of data used were extracted in 1985 and 2015 respectively. In their process of imaging, besides sensors, the climatic conditions such as atmosphere, temperature and light were not exactly the same in the process of imaging, leading to the great difference in the quality of image data. In this case, if decision tree is continues to be used to classify the images of 2015 and extract the Achnatherum splendens community, a large classification error is inevitable due to the choice of threshold value. Hence, in the extraction of the Achnatherum splendens community of 2015, this paper uses the method of change detection. Change detection refers to determining the change of the state of a certain surface feature or to determine the development of a certain phenomenon according to the numerous observation at different times. In the remote sensing, it refers to acquiring the image of the same area at many different times to determine a certain surface change[21]. Considering the splitting of the Achnatherum splendens community, we chose the change detection method based on the image segmentation, that is to set up the sample database in accordance to the geometric characteristics and spectral characteristics of the classification pattern spots of Achnatherum splendens community 
of 1985 as well as the field sampling points of 2015, to segment the image of 2015 and extract the pattern spots of Achnatherum splendens of 2015 referring to sample database. In this way, classification accuracy of Achnatherum splendens community could be improved and the continuity and unity of the results could be ensured.

Result Verification. The result verification and accuracy evaluation are the important steps of remote sensing interpretation. This paper uses the superposition comparison and the Kappa coefficient calculation to make accurate evaluation and verification of the interpretation results. Superposition comparison is to overlay the interpretation results classified with the decision tree of 2015 with the point's layer of field samples obtained in July 2015, then to make result verification through comparing and analyzing the number of sampling points falling in the corresponding pattern spots with the total sampling point of the type. Kappa coefficient is often used to evaluate the classification accuracy of remote sensing image. Its value range should be between -1 and 1 , higher Kappa value indicating the higher correctness and better consistency. According to the calculation of edge probability, when Kappa $>=0.75$, the consistency is good; when $0.4<=$ Kappa $<0.75$, the consistency is general; when Kappa $<0.4$, the consistency is poor [22-26].

\section{Results Analysis}

Through the superposition comparison of 69 Achnatherum splendens samples and the pattern spot interpreted in 2015, it's found that a total of 55 samples of Achnatherum splendens were exactly identical with the pattern spot of Achnatherum splendens. Six were located within 3 pixels of the spot edge. Take the weight and add together, the comprehensive goodness being $81 \%$ and the degree of overlap being higher. In the verification process of the Achnatherum splendens community classification result, it was found that Achnatherum splendens was easier to mix with wetland vegetation when it was near its edge. In a few areas, the stipa capillata vegetation had high intensity which was also easy to get mixed. The confounding matrix is constructed by using the actual sampling points, then calculation found that the overall accuracy of the change detection classification is $91.74 \%$, the Kappa coefficient 0.85 with high consistency.

Temporal and Spatial Variation of Achnatherum Splendens Community in Hulun Lake area. Fig. 3 shows that form 1985 to 2015, the distribution intensity of Achnatherum splendens community spot had significantly increased. In 1985, the Achnatherum splendens community was mainly distributed in the west and south of the Hulun Lake, less in other areas (Fig. 3a). In 2015, the Achnatherum splendens community was distributed throughout the whole research area, with a significant increase at the edge of northern wetland vegetation and a relatively average distribution in the remaining areas (Fig. 3b). By comparing the two distribution patterns of Achnatherum splendens, it could also be found in some areas Achnatherum splendens disappeared.
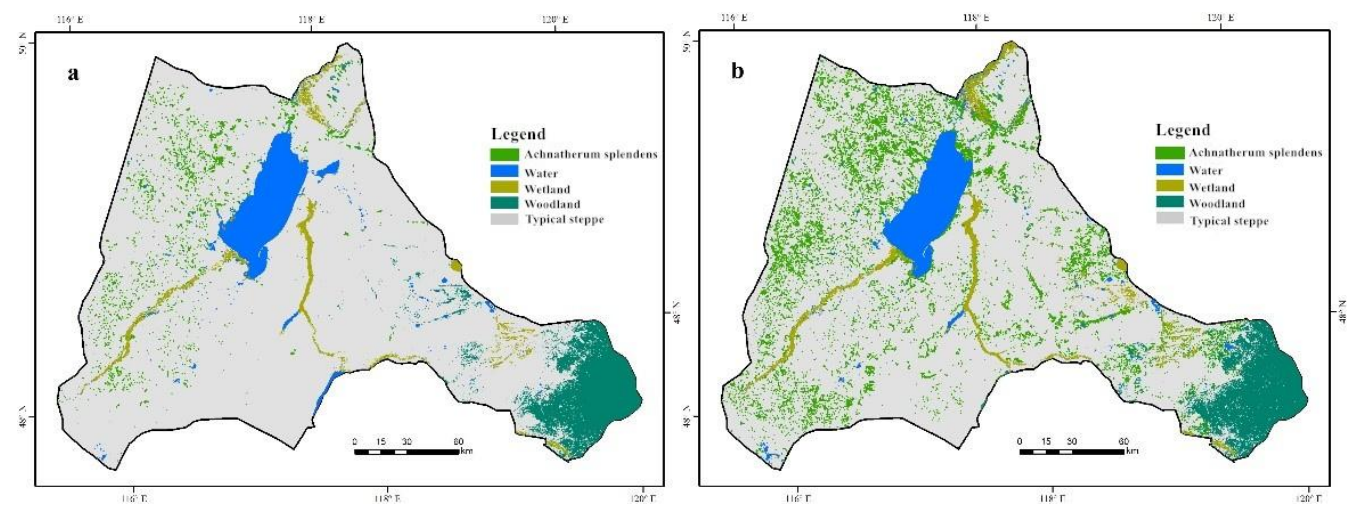

Figure 3. Distribution of Achnatherum splendens. a) 1985; b) 2015.

Fig. 4 shows that in the past 30 years, the number of Achnatherum splendens spots in Hulun Lake area has increased from 2929 to 22763, with the total area increasing from 53.56 ha to 201.95 ha. The number of Achnatherum splendens spots less than $0.5 \mathrm{hm}^{2}$ increased from 906 to 16031 , the 
proportion increasing from $30.93 \%$ to $70.43 \%$, as the fastest and the largest one. The big spots more than 1 square kilometer grows slow, increasing from 2 to 11.
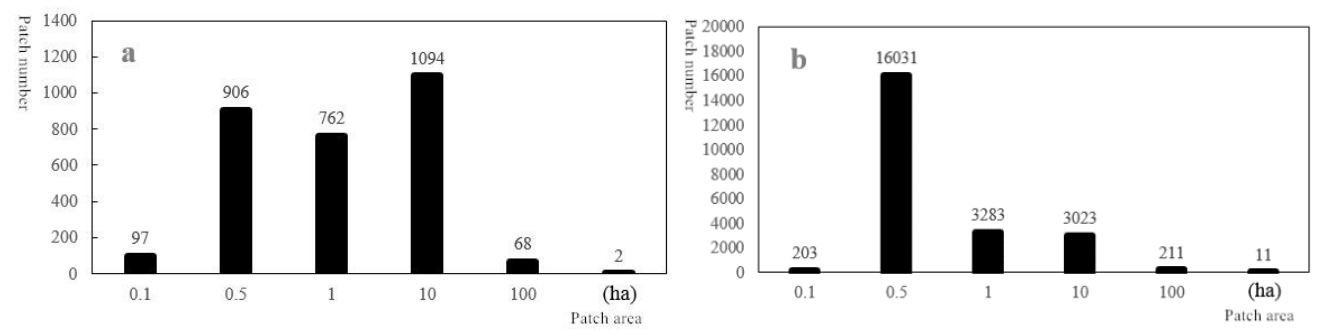

Figure 4. Patch count statistics for Splendens community. a) 1985; b) 2015.

Quality Characteristics of Achnatherum Splendens Community. The remote sensing vegetation index is an optical measure of vegetation biomass density, values of which have a significant linear relationship with vegetation biomass[27,28]. Fig. 5 shows that in Landsat OLI statistics of July 2015 the NDVI distribution curve of Achnatherum splendens community is significantly higher than that of typical steppe. The NDVI values of Achnatherum splendens are concentrated in the vicinity of 0.29 , while the values of typical steppe are mainly around 0.16 (Fig. 5a). The RVI distribution curve of is mainly near 1.82 (Fig. 5b), while that of the typical steppe is mainly near 1.38. It can be inferred that the biomass density of Achnatherum splendens community is significantly higher than that of typical steppe. In addition, the overlapping area of the NDVI distribution curve of Achnatherum splendens and typical steppe is less than that of RVI curve, showing the better separation which indicates that the selection of NDVI is of some advantage to identify Achnatherum splendens.
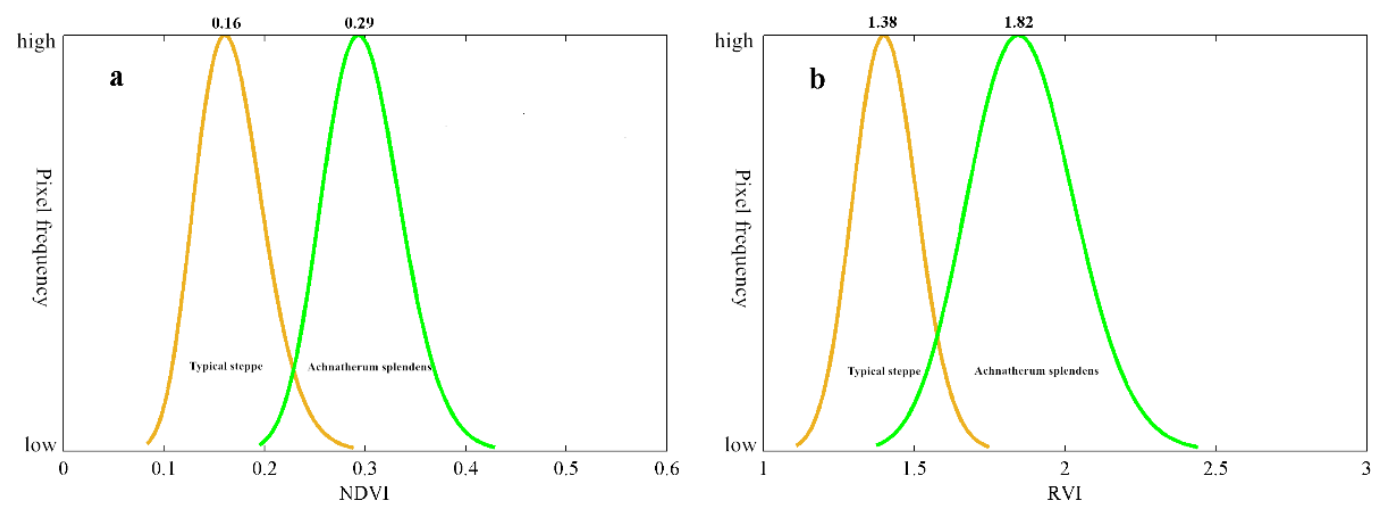

Figure 5. Frequency distribution of NDVI and RVI value for the typical steppe and Achnatherum Splendens community. a) 1985; b) 2015.

Factor Analysis of Distribution Terrain of Achnatherum Splendens Community. Terrain fluctuations will re-distribute water, heat, light and soil factors, thereby affecting the composition, structure and spatial layout of vegetation communities. As shown in Fig. 6, the distribution of Achnatherum splendens community increases rapidly with the rising of slope and then decreases rapidly. Few Achnatherum splendens communities are distributed on the flat surface with the slope of less than $1^{\circ}$; more than $90 \%$ are grown at the bottom and foot of the slope of less than $5^{\circ}$; no Achnatherum splendens community basically exists on the slope of above $10^{\circ}$. 

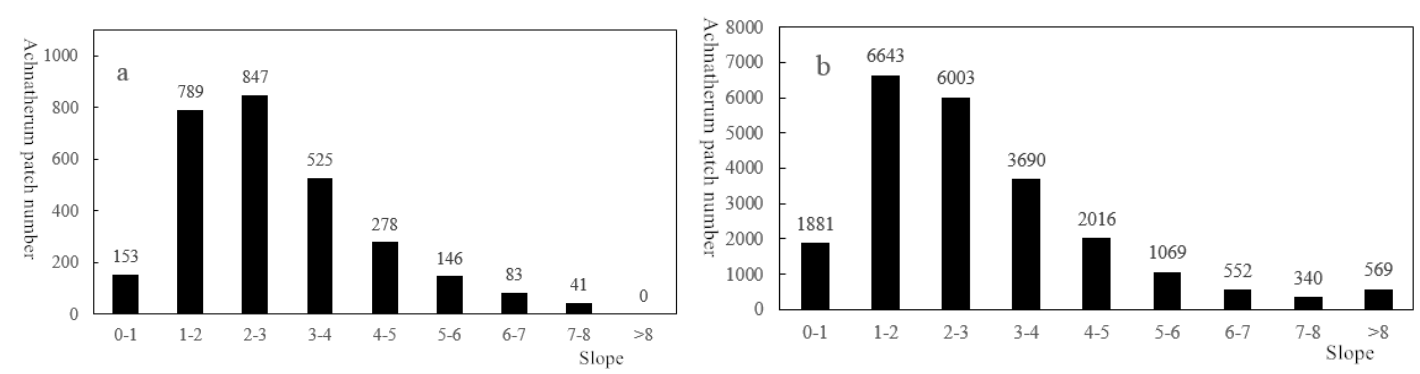

Figure 6. The slope of Achnatherum splendens community living. a) 1985; b) 2015.

The difference of the slope exposure will cause the diversity of water and solar radiation, thereby affecting the spatial distribution pattern of vegetation. According to the exposure distribution of Achnatherum splendens community(Fig. 7), it mainly grows in the southwest, south and southeast of the sunny slope, less in the northwest and north. The sunny slope has significantly more Achnatherum splendens community than shady slope.
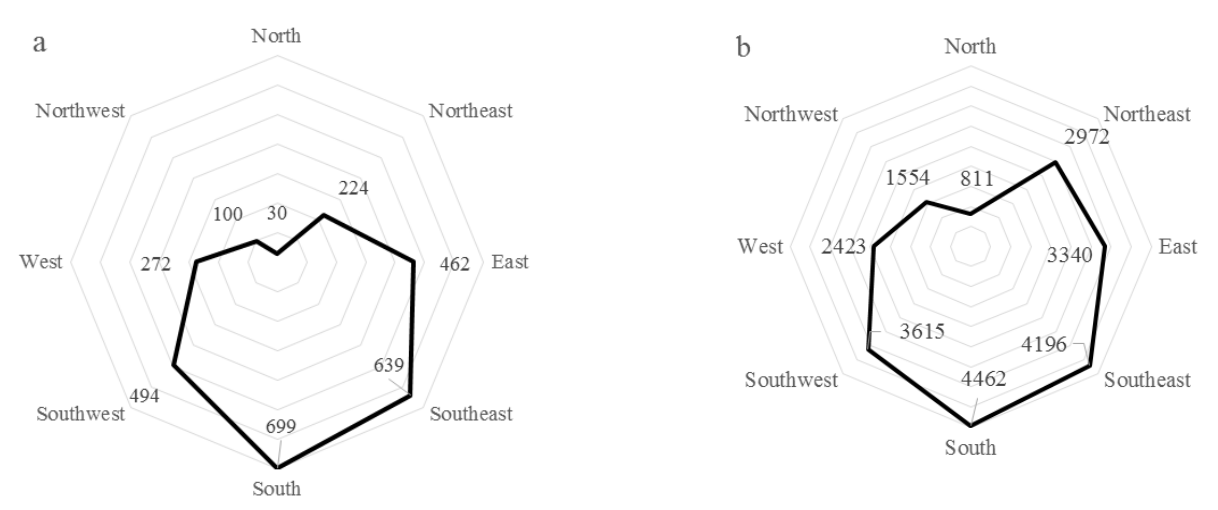

Figure 7. The slope aspect of Achnatherum splendens community living. a) 1985; b) 2015 .

\section{Discussion}

In recent decades, the less precipitation, rising temperatures and growing evaporation in the Hulun Lake area has led to the shrinking of the lake and the decrease of the surface runoff ${ }^{[12-14]}$. The typical steppe as the zonal vegetation in the Hulun Lake area has shown the trends of decreasing of vegetation coverage, declining of steppe height, degrading of dominant species and rising of weeds under the background of climate warming. The author finds that the Achnatherum splendens community as a non-zone steppe community sensitive to moisture demonstrates the trend of rising. Through the analysis of topographic factors, the author finds that the Achnatherum splendens community is mainly distributed in the bottom and foot of the sunny slope, which could be explained by the access to groundwater, surface runoff and convergence for it there ${ }^{[29]}$. The slope foot soil has much more nitrogen, phosphorus, potassium and other nutrient elements than the top which is conducive for the vegetation to obtain enough biochemical elements. Sunny slope enjoys stronger and longer sun light than the shady slope, as a consequence the total solar radiation is more. Therefore, in the condition of low slope and abundant water, the sunny slope enjoys the concentrated community of Achnatherum splendens. In recent years, the reduction of precipitation in the Hulun Lake area caused the delayed drainage of low-lying areas, resulting in the uplift of salinity in the deep soil and the secondary soil salinization [30]. And the Achnatherum splendens community as the salt-enduring vegetation of wide ecological amplitude shows good adaptability to the soil with high salt and good water condition. Therefore, under the background of the shrinking in regional lakes, the change of soil moisture and salinity may be the main reason for the increase of 
Achnatherum splendens community.

The foliage of Achnatherum splendens is relatively dense and the vertical structure of the community is quite obvious. When the habitat is suitable, it is easy to form dominant species of strong community aggregation[31]. It could be seen from the NDVI and RVI distribution curve of Achnatherum splendens and typical steppe that the index of Achnatherum splendens community is generally higher than that of typical steppe, indicating that the Achnatherum splendens community is a kind of vegetation with high biomass. From 1985 to 2015, the area of Achnatherum splendens had increased from 53.56 square kilometers to 203.95 square kilometers. In the case of the general degradation of the steppe ecosystem, as a vegetation community of high biomass [32], the increase in the area of Achnatherum splendens is conducive to consolidate and maintain the value of ecosystem services in the region and to ensure the production of animal husbandry.

This paper has done meaningful work in the research of the change trend of Achnatherum splendens community in Hulun Lake area for 30 years; however, there are some problems and shortcomings in the extraction of Achnatherum splendens community. First, the Achnatherum splendens community usually has strong tillering ability, which makes it the dominant species in suitable habitat[33]. It has wide canopy which makes it easy to grasp its pattern spot in multispectral remote-sensing image. But in present Hulun Lake area, the Achnatherum splendens community belongs to the non-zonal vegetation, together with the dynamic change of its habitat, which makes it easy to mix other vegetation types into some parts of Achnatherum splendor. In the course of the actual investigation, it is found that some of the Achnatherum splendens is mixed with a small amount of Stipa, Alkaline grass or other salt-borne vegetation. The reflectivity of the mixed vegetation is lower than that of the Achnatherum splendens, which decreases the precision of the extraction. Second, from the NDVI and RVI distribution curve of Achnatherum splendens and typical steppe, some overlapping areas can be found. This paper uses NDVI to distinguish between Achnatherum splendens and typical steppe, during which a small number of mixing phenomena are inevitable.

Monitoring changes in regional ecological environment by remote sensing technology is a commonly used tool but it is usually limited by the time and spatial resolution. UAV remote sensing is a new means in the application of vegetation monitoring, which has the advantages of flexibility, high resolution and low cost. Therefore, combing the UAV remote sensing monitoring will effectively improve the identification accuracy of Achnatherum splendens community. In this paper, the NDVI vegetation index is used in the extraction of Achnatherum splendens. Although it makes a good separation of the Achnatherum splendens community and typical steppe, there are still some overlapping areas, which are mainly limited by spectral resolution. In contrast, hyperspectral remote sensing has a distinct advantage in vegetation type identification ${ }^{[34]}$. Therefore, extracting the feature information of Achnatherum splendens community with hyperspectral remote sensing technology will effectively improve the problem of information overlapping in multi-spectral remote sensing classification.

\section{Conclusion}

(1) People can effectively extract the distribution information of Achnatherum splendens community using NDWI, NDVI and DEM information through the establishment of decision tree classification and the method of change detection. The accuracy of result verification reaches $81 \%$ and Kappa coefficient reaches 0.85 , which achieve relatively high recognition accuracy.

(2) From 1985 to 2015, the number and area of Achnatherum splendens pattern spots in Hulun Lake area have increased significantly, with 19834 more pattern spots and 148.39 larger square kilometers of the total area. The data shows a growing trend from less to more and out of nothing. The west of Hulun Lake area enjoys more obvious increase.

(3) Through terrain analysis of the region where pattern spots of Achnatherum splendens locates in 2015, it's shown that the Achnatherum splendens community is mainly distributed in the low-lying sunny area of smaller slope $\left(<5^{\circ}\right)$, indicating that the distribution area of Achnatherum splendens community is directly related with water, salt, nutrient, light and other natural elements. 


\section{References}

[1] H.B Zhang, G.X Yang, Q Huang, et al. Analysis of dynamic spatial-temporal changes of landscape patterns in Hulunber meadow steppes-Taking Hailaer and surrounding areas as an example . Acta Prataculturae Sinica, 2009, 18(1):134-143.

[2] H.C. Zhang, M.J. Wang, L. Zhang, et al. Response of meadow steppe ANPP to climate change in Hulunbeir, Inner Mongolia-a simulation study. Acta Prataculturae Sinica, 2013, 22(3):41-50.

[3] H. Zhang, Z. Fan ,et al.Impact Of Global Change On Salinized Meadow In North Of Tarim Basin. Arid Land Geography, 1998(4):16-21.

[4] X.L. Chang, S. H. Lv, C.Y. Feng, et al. Impact of topography on the spatial distribution pattern of net primary productivity in a meadow. Acta Ecologica Sinica, 2015, 35(10):3339-3348.

[5] Q.Q. Liu, W.B. Yang, D. Shan. Effect of Soil Moisture on Biomass of Meadow Steppe. Journal of Arid Land Resources and Environment, 2005, 19(z1):179-181.

[6] X. Chai, C.Z. Liang, M.W. Liang, et al. Seasonal dynamics of belowground biomass and productivity and potential of carbon sequestration in meadow steppe and typical steppe, in Inner Mongolia, China. Acta Ecologica Sinica, 2014, 34(19):5530-5540.

[7] J.L. He, D. Shan, Z.Q. Liang, et al. Effects of Climate Change on Meadow Grassland Community in Inner Mongolia. Research of Soil and Water Conservation, 2009, 16(5):131-134.4

[8] Bruelheide $\mathrm{H}$. Translocation of a montane meadow to simulate the potential impact of climate change[J]. Applied Vegetation Science, 2003, 6(1):23-34.

[9] Y.T. Yin, X.Y. Hou, X.J. Yun. Advances in the climate change influencing grassland ecosystems in Inner Mongolia[J]. Pratacultural Science, 2011.

[10]X.Q. Fang, Y.U. Wei. PROGRESS IN THE STUDIES ON THE PHENOLOGICAL RESPONDING TO GLOBAL WARMING[J]. Advance in Earth Sciences, 2002.

[11] J. Lv, L.M. Liu. The Study on Inner Mongolia Grassland Sustainable Development Based on Human - land Relationship. Journal of Arid Land Resources and Environment, 2007, 21(11):80-84.

[12] X. Cao, Z.H. Gu, J. Cheng, et al. Analysis Of Human_ Induced Steppe Degradation Basedon Remote Sensing In Xilin Gole, Inner Mongolia, China. Chinese Journal of Plant Ecology, 2006, 30(2):268-277.

[13]ZHANG N, WU L-J, LIU S-T, et al. The characteristics of climate change and its influence on water area of Hulun lake. Journal of Arid Land Resources and Environment, 2015, 29(7):192-197.

[14] C. Li, W. Ma, X.X. Shi, et al. Reconstruction of the hydrology series and simulation of salinity in ungauged Lake Hulun . Journal of Lake Sciences, 2006, 18(1):13-20.

[15] J. Zheng, C. Ke, Z. Shao, et al. Monitoring changes in the water volume of Hulun Lake by integrating satellite altimetry data and Landsat images between 1992 and 2010. Journal of Applied Remote Sensing, 2016, 10(1).

[16] H.Y. Zhao, L.J. Wu, W.J. Hao. Influences of climate change to ecological and environmental evolvement in the Hulun Lake wetland and its surrounding areas. Acta Ecologica Sinica, 2008, 28(3):1064-1071.

[17] Y.R. Gu, S.H. Li, H.Y. Zhao,et al. Responses of runoff in Hulun Lake basin of Inner Mongolia to climate change. Chinese Journal of Ecology, 2012,31( 6) : 1517-1524 
[18] G.L. Zhang, X.L. Xu, C.P. Zhou, et al. Responses of Vegetation Changes to Climatic Variationsin Hulun Buir Grassland in Past 30 Years. ACTA GEOGRAPHICA SINICA2011,66(1):47-58

[19] Y.F. Zhang, W. Wang, C.Z. Liang, et al. Suitable habitat for the Achnatherum splendens community in typical steppe region of Inner Mongolia. Acta Ecologica Sinica, 2012, 32(4):1193-1201.

[20] X.J. Shen, D.W. Zhou, F. LI, et al. Vegetation Change and Its Response to Climate Change Vegetation Change in Grassland Region of China in China. Scientia Geographica Sinica, 2015, 35(5):622-629.

[21]B.C. Gao. NDWI-A normalized difference water index for remote sensing of vegetation liquid water from space. Remote Sensing of Environment, 1997, 58(3):257-266.

[22] G.L. Gao, S.Y. Wang. Compare Analysis of Vegetation Cover Change in Jianyang City Based on RVI and NDVI[C]// International Conference on Remote Sensing, Environment and Transportation Engineering. 2012:1-4.

[23] W.M. Shen, W.J. Wang, H.J. Luo, et al. Classification Methods of Remote Sensing Image Based on Decision Tree Technologies. Remote Sensing Technology and Application, 2007, 22(3):333-338.

[24]X.X. Sun, J.X. Zhang, Q. Yan, et al. A Summary on Current Techniques and Prospects of Remote Sensing Change Detection. Remote Sensing Information, 2011, 2011(1):119-123.

[25] Congalton R G, Mead R A. A quantitative method to test for consistency and correctness in photointerpretation. Photogrammetric Engineering \& Remote Sensing, 1983, 49(1):69-74.

[26] Congalton R G, Oderwald R G, Mead R A. Assessing Landsat classification accuracy using discrete multivariate analysis statistical techniques. Agricultural \& Biological Chemistry, 1984, 44(5):1003-1007.

[27]F. Li, Y. Zeng, J. Luo, et al. Modeling grassland aboveground biomass using a pure vegetation index[J]. Ecological Indicators, 2016, 62: 279-288.

[28]F. Li, X. Wang, J. Zhao, et al. A method for estimating the gross primary production of alpine meadows using MODIS and climate data in China[J]. International Journal of Remote Sensing, 2013, 34(23): 8280-8300.

[29] X.J. Xu, H.H. Liu, P.C. Zhang. Effects of slope position on soil water content and soil depth in the Hulunbeier grassland. Journal of Arid Land Resources and Environment, 2010, 24(4):180-184.

[30] Y.Q. Zhang, C.Z. Liang, W. Wang, et al. Soil salinity and Achnatherum splendens distribution. Chinese Journal of Ecology, 2010, 29(12):2438-2443.

[31] G.Y. Zhou, G.C. Chen, G.Y. Wei, et al. Distribution Patterns of Major Populations in Achnatherum splendens Communities of Qinghai Lake Area. Acta Botanica Boreali-Occidentalia Sinica, 2006, 26(3):579-584.

[32] R.J. Wang, Z.H. Qin, L.P. Jiang, et al. Lost value of Chinese grassland ecosystem due to degradation:An estimate based on remote sensing. Chinese Journal of Ecology, 2007, 26(5):657-661.

[33] G.Y Zhou, G.C. Chen, Y.L. Zhao, et al. Study on Achnatherum splendens community characteristics and species diversity around Qinghai Lake. Acta Botanica Boreali-Occidentalia Sinica, 2003, 23(11):1956-1962. 
[34] L Zhou, X.P. Xin, G Li, et al. Application progress on hyperspectral remote sensing in grassland monitoring. Acta Prataculturae Sinica, 2009, 26(4):20-27. 